\title{
Variation in plastid inheritance between pelargonium cultivars and their hybrids
}

\author{
R. A. E. Tilney-Bassett and \\ A. B. Almouslem
}

School of Biological Sciences, University College of Swansea, Singleton Park, Swansea SA2 8PP, Wales, U.K.

The genetic control of plastid inheritance is analysed in cultivars and hybrids of zonal pelargoniums (Pelargonium $\times$ Hortorum Bailey).

After crosses between maternal parents with normal green (G) plastids and paternal parents with mutant white (W) plastids in their germ cells, the progeny consist of a mixture of green, variegated and white embryos corresponding to a maternal, biparental or paternal inheritance of plastids in each individual. Families of individual embryos from selfed or crossed parents are of two patterns that are highly dependent upon the genotype of the female parent. Type I females produce families in which green embryos are most, variegated intermediate and white least frequent. Type II females produce families in which green and white embryos are of approximately the same frequency and variegated embryos the least frequent.

Five type I and six type II cultivars and several hybrids between them were selfed, and 88 crosses of various kinds were made to create a heterogeneous population of 2601 plants that were tested for their plastid inheritance pattern by crossing with a standard male parent as source of mutant plastid; 1298 families were classified as type $I$ and 1303 as type II. The maternal $(G+V)$, biparental $(V)$ and paternal $(V+W)$ plastid percentage transmission was estimated for each family, and the frequencies of percentage classes within the population of type I or type II families expressed as histograms. The type I families fell into a skewed distribution with such a maternal bias that about one-half inherited only maternal plastids, and over two-thirds of them had at least some maternal plastids in every embryo. The average family had a maternal percentage of 98.7 per cent and paternal of 4.7 per cent, and no family was below 80 per cent maternal or above 25 per cent paternal. The overall maternal : paternal ratio was about $21: 1$. The type II families were more normally distributed with a large variance. The average family had a maternal percentage of 63.2 per cent and paternal of 38.1 per cent with an overall maternal : paternal ratio of about $5: 3$. On average 46.6 per cent of type I families and 64.7 per cent of type II families had biparental progeny. The frequencies of families decreased sharply with increasing proportions of biparental progeny.

Analysis of variance of a subset of the type II population showed that there was a significant added variance component for maternal percentage, and a significant linear regression of offspring on parents; hence, in addition to the major gene difference determining type I versus type II patterns, there was a significant polygenic component causing variations within each pattern.

Alternative hypotheses for the mechanisms determining differences in the pattern of plastid inheritance in Pelargonium, Oenothera, and Medicago are discussed.

\section{INTRODUCTION}

The use of the fluorochrome 4'6-diamidino-2phenyl-indole (DAPI) to detect plastid DNA in generative and/or sperm cells of pollen from 235 flowering plant species, has led Corriveau and Coleman (1988) to conclude that biparental inheritance of plastids may occur in about 14 per cent of genera, with examples scattered among 19 per cent of the 80 families examined. Their study confirmed the majority of biparental species pre- viously identified by electronmicroscopic and/or genetic evidence (Kirk and Tilney-Bassett, 1978; Sears 1980). As well as the traditional white (albino) plastid mutants, inheritance studies are now using mutants with resistance to herbicide or antibiotic, or plastids differing in a biochemical marker (Börner and Sears, 1986). Moreover, the detection of the inheritance pattern has been improved with the help of tissue culture (Medgyesy et al., 1986) and the analysis of chloroplast DNAs, as recently reviewed by Smith (1988a). A par- 
ticularly interesting approach for the analysis of competition between plastids is the creation of hybrid and cybrid cells by protoplast fusion (Kumar and Cooper-Bland, 1986; Kumar and Cocking, 1987). In the present paper, however, we shall report results from making crosses between plants containing green $(\mathrm{G})$ or white $(\mathrm{W})$ plastids in their germ cells, as these have contributed to our interest in the genotypic control of biparental plastid inheritance.

During interspecific $\mathrm{G} \times \mathrm{W}$ crosses in Oenothera, Schötz $(1954,1968,1974,1975)$ discovered that the biparental plastid inheritance was strongly biased towards the maternal parent. Nevertheless, there was considerable variation, which he attributed to differences in the ability of wild-type plastids to multiply in competition with a constant source of mutant plastids. When Chiu et al. (1988) reciprocally crossed four wild-type plastids with seven plastid mutants in a constant nuclear background, they confirmed the highly significant role of the plastome in the process of plastid transmission. They concluded that differences in the multiplication rates were important but insufficient to explain all the results.

In Pelargonium the study of biparental plastid inheritance has been largely within cultivars, and differences that exist between plastid mutants have not been studied extensively (Abdel-Wahab and Tilney-Bassett, 1981). Instead, most attention has been given to the important role played by the nuclear genome. After $\mathrm{G} \times \mathrm{W}$ crosses the progeny consist of a mixture of green, variegated and white embryos. Families of individual embryos from selfed or crossed parents are of two patterns that are highly dependent upon the genotype of the female parent. Type I females produce families in which green embryos are most, variegated intermediate and white least frequent. Type II families produce families in which green and white embryos are of approximately the same frequency and variegated embryos the least frequent. The two patterns were considered to be under the control of a major nuclear gene, which was symbolized as $P r$, with alternative alleles $\operatorname{Pr} 1$ and $\operatorname{Pr} 2$, on the assumption that the gene controlled plastid segregation through an effect, direct or indirect, on plastid replication (Kirk and Tilney-Bassett, 1978; TilneyBassett, 1988). The further analysis of the $\operatorname{Pr}$ locus may be separated into its behaviour as a major Mendelian switch gene (Tilney-Bassett and Abdel-Wahab, 1982; Tilney-Basset, 1988), which we shall not discuss further here, and into the secondary causes for the wide variability in gene expression.
An insight into the nature of the population variability was begun with the analysis of variance of $36 \mathrm{G} \times \mathrm{W}$ and 36 reciprocal $\mathrm{W} \times \mathrm{G}$ crosses (Tilney-Bassett, 1976). This was followed by examining the variation between 214 families, which showed signs of a skewed or normal distribution among type I or type II plants respectively (TilneyBassett 1984). The investigation has now been expanded by observing the behaviour of a much larger population.

The importance of the nuclear genotype has recently been discovered in other plants. Normally plastid inheritance in Petunia is maternal (Corriveau and Coleman, 1988), and this was confirmed by Cornu and Dulieu (1988) in crosses between inbred lines and a viable, virescent plastid mutant of $P$. hybrida "Blue Bedder". But one line, Tbl-3, consistently produced up to 2 per cent variegated seedlings indicating a low level of pollen transmission. This was confirmed by creating, through recurrent backcrosses, a strain consisting of the Tbl-3 nucleus of $P$. hybrida and the normal green plastids of $P$. parodii. The advantage of this combination was that the $P$. parodii plastids produced a $7.4 \mathrm{kbp}$ fragment, when treated with the BamH1 restriction enzyme, that was absent from the $P$. hybrida plastid DNA. Hence the phenotypic difference between plastids could be supported by molecular examination, and this was used to prove that the Tbl-3 genotype allowed 1-2 per cent pollen transmission whether the pollen transmitted normal or mutant plastids, and whether the normal plastids were from $P$. hybrida or $P$. parodii.

Another carefully analysed example was found in Medicago sativa by Smith (1988b), who found a regular biparental inheritance of plastids with a strong paternal predominance, and a high frequency of purely paternal progeny. Differences were found in the precise inheritance patterns, which were influenced by both maternal and paternal genotypes.

These examples show the importance of the genotype in controlling plastid inheritance, and make it clear that the alternatives of uniparental or biparental inheritance are not necessarily fixed but may often be reversible conditions with the possibility of selection changing the population frequencies in either direction.

\section{MATERIALS AND METHODS}

The cultivars of zonal pelargonium (Pelargonium $\times$ Hortorum Bailey) are classified into two types. The type I are "Alde", "Dolly Varden", "Fleurette", 
Lass O'Gowrie" and "Miss Burdette-Coutts". he type II are "Flower of Spring", "Foster's zedling", "Hills of Snow", "J. C. Mapping", "Pac rosser Garten" and "Verona".

Over several years all 11 cultivars and a few ybrids between cultivars were selfed, and 88 uclear crosses (not distinguishing separate plastid osses) were made either within and between the sltivars, or between F1s and a parental cultivar, $r$ within and between $F 1 s$. The programme created heterogeneous collection of green progeny of hich 2601-called families-were tested for the 'pe I or II phenotype. Each family was tested by rossing as female parent with the variegated form f "Flower of Spring" as male parent, and scoring 1e resulting embryos.

The standard male parent is a GWG lesochimera carrying mutant white plastids in its erm cells (Tilney-Bassett, 1986). After $\mathrm{G} \times \mathrm{W}$ rosses, the progeny fell into a type I or type II egregation pattern (see Introduction). In some ype I families there were green and variegated but o white embryos, and in others neither variegated or white embryos. In type II families, green and thite embryos were both more frequent than varieated embryos. For over 95 per cent of families he classification worked well, for the remainder dditional ways of separating type I and type II lants were required. Hence, when for a type II lassification the frequency of green embryos was ery high, it was decided that at least 6 per cent if embryos should be variegated plus white, and here should be at least three more white than ariegated embryos in order to qualify as type II, nd when variegated embryos were absent at least i per cent of embryos should be white. And, when he frequency of variegated embryos was high, here should be at least three more white than ariegated embryos. At least 20 embryos were cored for each family. Altogether, 194,008 :mbryos were scored-an average of 74 embryos ser family.

In previous experiments (Tilney-Bassett and 3irky, 1981), similar data were used to estimate lastid allelic frequencies as measured by the relaive contributions of green and white plastids tveraged across the population of embryos derived rom each family, after allowing for the proporions of green and white tissue in each variegated imbryo. After $\mathrm{G} \times \mathrm{W}$ crosses, green, variegated and white embryos were scored as maternal, biparental and paternal zygotes respectively; an estimate of he maternal zygote frequency excluded biparental zygotes, but an estimate of the maternal allelic irequency, equivalent to the green plastid allelic frequency, took account of biparental zygotes. In the present experiments, neither maternal zygotes nor maternal allelic frequencies were measured. This is because we set out to estimate, for each family, the percentage of zygotes with at least some plastids derived from the maternal parent. This maternal plastid percentage is calculated from the sum of the maternal plus biparental zygotes. Conversely, the paternal plastid percentage is calculated from the sum of the paternal plus biparental zygotes. The measure differs from the allelic frequency estimates because no account is taken of the proportions of maternal and paternal plastids within the biparental zygotes, which were not scored. In fact, the frequency of biparental zygotes was usually less than 20 per cent with "Flower of Spring" as the source of white plastids (TilneyBassett, 1976), and so the difference is not great. In families without variegated progeny, the frequency of maternal zygotes, the maternal allelic frequency, and the maternal plastid percentage are identical. The biparental percentage is the percentage of biparental zygotes, that is variegated embryos, within a family.

\section{RESULTS}

Of 2601 families tested, 1298 were classified as type I and 1303 as type II. For each family, frequencies of green, variegated and white embryos were converted into percentages; these are estimates of the average proportions of maternal, biparental and paternal zygotes for the population of embryos borne to each family. For each family, three values were measured-the maternal plastid percentage (maternal plus biparental zygotes), the biparental percentage (biparental zygotes), and the paternal plastid percentage (paternal plus biparental zygotes). The families, within type I and within type II, were next classified into groups with either 100 per cent maternal plastid percentage, or with successively lower values descending in four per cent intervals, and the frequencies of each group scored. The paternal plastid percentages were grouped and their frequencies scored in similar fashion; the biparental percentages were grouped in two per cent intervals.

The frequencies of maternal and paternal plastid percentages among type I families are shown in a histogram (fig. 1). The families fell into a very skewed distribution with such a strong maternal bias that over 70 per cent of them had at least some maternal plastids in every zygote. Thereafter, 


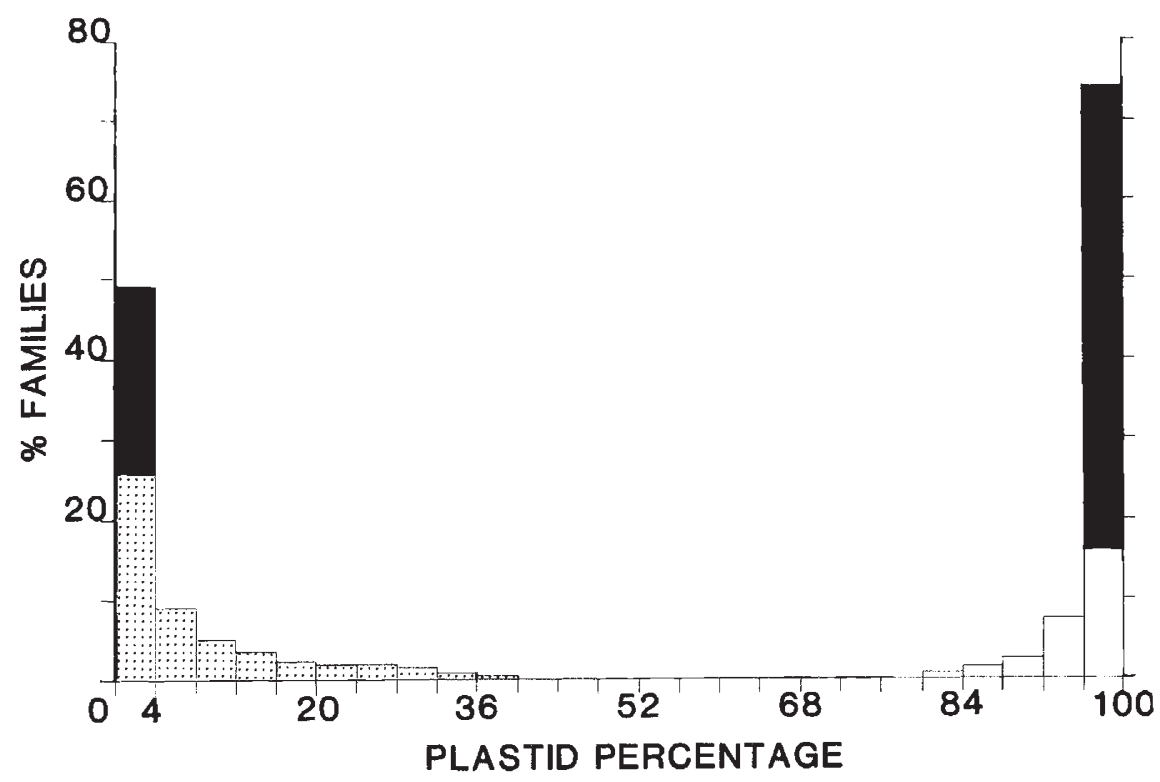

Figure 1 The frequencies of type I families with respect to the percentages of zygotes (embryos) with paternal (stippled) and with maternal (open) plastids. The frequency of families with no paternal plastids (left) and with 100 per cent maternal plastids (right) is shown in black.

frequencies of families with a maternal plastid percentage less than 100 per cent fell off steeply, and no family fell below 80 per cent. The average family had a value of 98.7 per cent. The strong maternal bias was also expressed in the frequency distribution of the paternal plastid percentage. Almost 50 per cent of families had a paternal percentage of zero-they had neither paternal nor biparental zygotes. Thereafter, frequencies of increasing paternal contribution fell sharply at first and then more gently; less than 5 per cent of families had a paternal plastid percentage greater than 25 per cent, and no family reached 50 per cent. The average family had a value of 4.7 per cent. The ratio of the maternal: paternal percentage of $98 \cdot 7: 4 \cdot 7$ for the average family is equivalent to a maternal bias of approximately $21: 1$.

Among those families with biparental progeny, the maternal:paternal percentage ratio ranged from a very rare $96: 1$ to $8: 1$. Within this range we found a highly significant correlation $(r=-0.725)$ between a decrease in the ratio and an increase in the frequency of biparental progeny. Moreover, from the regression equation, the frequency of biparental progeny was expected to remain at zero until the ratio fell to $19: 1$ or below.

The frequencies of maternal and paternal plastid percentages among type II families were more normally distributed with a large variance (fig. 2 ). The maternal plastid percentage fell into a range from 24 to 96 per cent with a mode at $60-64$ pel cent, and a family average of $63 \cdot 2$ per cent. The paternal plastid percentage fell into a range from 4 to 80 per cent with a mode at $40-44$ per cent. and a family average of $38 \cdot 1$ per cent. Hence, approximately 85 per cent of families expressed a maternal bias and 15 per cent a paternal one, o1 were equal. The ratio of the maternal:paterna: percentage of $63 \cdot 2: 38 \cdot 1$ for the family average is equivalent to a maternal bias of approximately $1 \cdot 66: 1(5: 3)$.

The maternal: paternal percentage ratio variec from a rare $3: 1$ to $1: 1$ but, unlike the type I plants there was no correlation $(r=0.067)$ between the ratio and the frequency of biparental progeny.

Families with variegated progeny totalled 60 s (46.6 per cent) among type Is and $843(64.7$ pe cent) among type IIs. Among families with varie gated embryos, the most frequent group were thos with less than 4 per cent biparental zygotes Thereafter, the frequencies of families with increasing percentages of biparental zygotes fel sharply at first and then more gently (fig. 3). Only about 10 per cent of families had more than 21 per cent of biparental zygotes, which were largely from type Is; no family reached as high as 40 pe: cent biparental zygotes.

Within the overall data, there exists subsets o a number of cultivars (or hybrids) from whick there are scores of their progeny derived by sel 


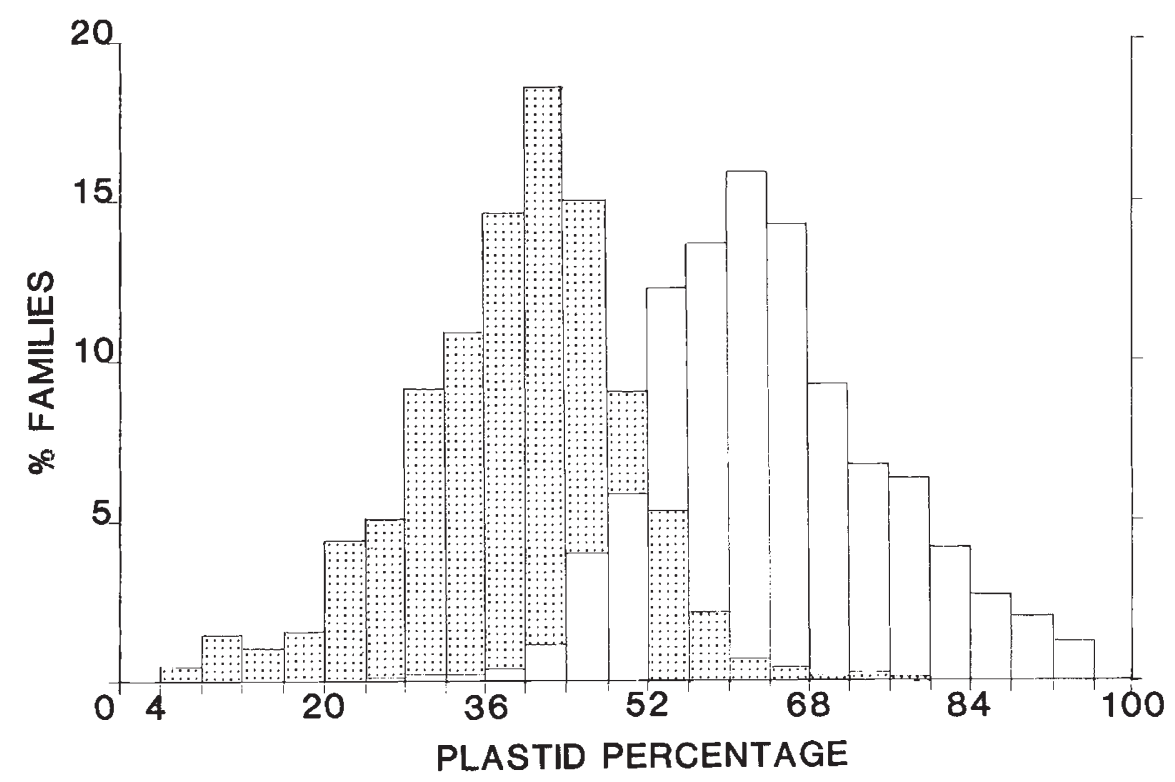

Figure 2 The frequencies of type II families with respect to the percentage of zygotes (embryos) with paternal (stippled) and with maternal (open) plastids.

pollination. This data can be used to separate the variation between cultivars from the variation within them, and to determine the variance attributable to the linear regression of offspring on parents. A useful subset was of 137 type II progeny derived from nine type II cultivars. Although these were representatives of a fairly normal distribution (fig. 2), the nine cultivars were not equally distributed across the range of maternal percentages-one was about 20 per cent above average, one 10 per cent above average, six within 5 per cent of average, and one 10 per cent below average.

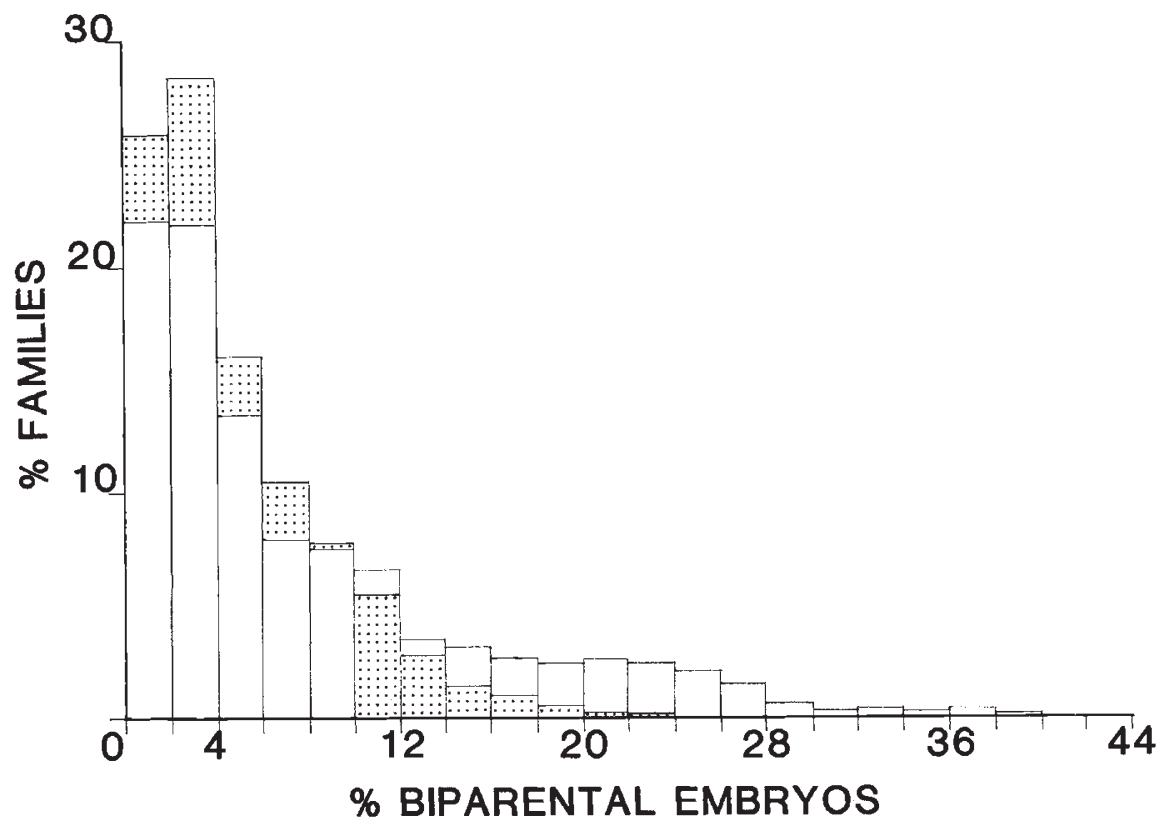

Figure 3 The frequencies of families with biparental zygotes (embryos), showing both type II (stippled) and type I (open) families. Frequencies of families with no biparental progeny, which are not illustrated, were $35 \cdot 3$ per cent type II and $53 \cdot 4$ per cent type 1 . 
The progeny varied from a random to a complete sample of all the plants that flowered and were fertile. So as to improve the conformity with the requirements of the analysis of variance, the percentages were transformed to angles prior to analysis. The data did not conform perfectly with the requirements of the analysis of variance-the variances among the nine groups of progeny were heterogeneous at the 5 per cent level. The values for two of the progeny were outliers; however, when the analysis was repeated with these completely removed, the $F$-ratios were reduced only slightly. The table (outliers included) shows that the variation between cultivars was highly significant at the $0 \cdot 1$ per cent level (table 1), which

Table 1 Regression analysis of the percentage maternal plastid transmission of variable numbers of type II offspring on nine selfed culivars

\begin{tabular}{lrrrr}
\hline $\begin{array}{l}\text { Source of variation } \\
\text { df }\end{array}$ & M.S. & $F$ & $P$ \\
\hline $\begin{array}{l}\text { Between groups } \\
\quad \text { cultivars) }\end{array}$ & 8 & 488.1215 & 13.262 & $<0.001$ \\
$\begin{array}{l}\text { Linear regression } \\
\text { Deviations from } \\
\text { regression }\end{array}$ & 1 & 2118.9843 & 8.298 & $<0.05$ \\
$\begin{array}{l}\text { Within groups } \\
\text { Total }\end{array}$ & 128 & 36.8060 & & \\
\hline $\begin{array}{l}\text { Linear regression } \\
\text { Pooled (Deviations } \\
\text { from regression } \\
\quad 135 \\
\quad \text { Within groups) }\end{array}$ & 136 & 2188.9843 & 7.252 & $<0.01$ \\
\hline
\end{tabular}

is indicative of significant genetic differences. The variance between cultivars was estimated as $45 \cdot 3$ per cent compared with 54.7 per cent within them. The variance attributable to the linear regression of offspring on parents was significant at the 5 per cent level when compared with the component due to the deviations from regression, but this was not very satisfactory as the latter was itself highly significant. Hence the $F$-ratio for linear regression was determined by comparing its mean square with the mean squares for deviations from regression and within groups pooled. This returned an $F$-ratio for linear regression significant at the 1 per cent level. The regression coefficient, $b_{v, x}$, was 0.620 , which is an estimate of the heritability, but the 95 per cent confidence limits varied from $0 \cdot 164$ to 1.076 , which is a very broad band. The expression for the regression equation was $Y=$ $18 \cdot 654+0 \cdot 620 X$.

We have not made a similar analysis of a subset of type I progeny because of the highly skewed distribution of the maternal plastid percentage (fig. 1) among type I plants.

\section{DISCUSSION}

The population analysis demonstrates the wide variation in the expression of the $P r$ gene, and how much this is modified by the genetic background, as well as the error variance around each genotype. For both segregation patterns there is a significant added variance component for the percentage maternal plastids indicative of polygenic effects which, coupled with the environmental variance, become submerged into the continuous variation so alike many another metrical character. The high mean for the percentage maternal plastid transmission among type I plants creates a very skewed distribution, whereas the lower mean among the type II plants allows for a more normal distribution around the mean. Further analysis of the latter distribution, which drawn from much the same population must contain a similar range of polygenes as exists among the skewed distribution, shows that the added variance component is highly significant. Moreover, the regression of offspring on parents demonstrates a significant heritable component.

A particularly interesting result was that about half the type I families exhibited a maternal transmission. Even when the polygenic combination permitted the transmission of male plastids, the average female plastid transmission remained much higher than for the male. Hence these plants included genotypes that exhibit a typical maternal plastid inheritance as well as genotypes allowing a modicum of biparental inheritance.

Possible mechanisms to explain biparental inheritance have been considered by different authors, but none have yet claimed to have found the complete answer. Russell $(1986,1987)$ has advised us to think about the numerical variation in the plastids: In Impatiens glandulifera, RichterLandmann (1959) estimated that the zygote contained 150-480 maternal and 20 paternal plastids to give a ratio from 24 to $7 \cdot 5: 1$. Meyer and Stubbe (1974) estimated that the zygote of Oenothera erythrosepala contained 25-32 maternal and 8-13 paternal plastids to give a ratio from 4 to $2: 1$. Russell has shown that in Plumbago zeylanica the male gamete that fuses with the egg at fertilization contains an average of 24.3 plastids, and the egg an average of 730 plastids. Hence, the ratio of maternal: paternal plastids is 30:1 (Russell says 
$54: 1$ !). The average maternal: paternal percentage plastid ratio in Pelargonium fits closest to the Impatiens estimate among type I families and with the Oenothera estimate among type II families. If there is such a differential input of plastids as between type I and II families, this comes about through the action of the alternative $\operatorname{Pr}$ genotypes on the number of maternal plastids as the paternal source was constant. But the observed output frequencies are not necessarily an accurate measure of the input frequencies.

Chiu et al. (1988) rejected the idea that differences between Oenothera crosses were related to variable input frequencies. They favoured a twopart explanation: They suggested that multiplication of the paternal plastids often lagged behind that of maternal plastids in the zygote so decreasing the probability of them entering the terminal cell and lowering the frequency of biparental progeny. Later, during embryo development, they believed that the success of alternative plastid types in a mixed population was more dependent on their relative rates of multiplication so that in some progeny the paternal plastids then became significantly more successful.

In his review of organelle heredity, Birky (1983) argued that the frequency distributions seen for chloroplast genes in Chlamydomonas (Birky et al., 1981) and for mitochondrial genes in yeast (Thraikill et al., 1980) were the consequence of random drift. Similarly, the distributions seen after Pelargonium crosses (Tilney-Bassett and Birky, 1981) supported the principle that the segregation and/or replication of plastids and plastid DNA appeared to have a strong random element which resulted in random drift of gene frequencies within the zygote and subsequent mixed cells. This, coupled with selection, led to a fixation of alleles giving many purely maternal or paternal embryos, and even whole progenies having maternal or paternal inheritance patterns, or with extremely high variance of gene frequencies.

The drift hypothesis stemmed from a need to explain the behaviour of chloroplast and mitochondria in the unicellular alga and fungus, and although the hypothesis was applied to the data from Pelargonium (Tilney-Bassett, 1988), the arguments were not completely convincing. On the one hand, there is no direct evidence for the extensive plastid turnover in zygotes needed for drift alone to operate and, on the other hand, the possible spatial separation of the plastids in the zygote coupled with the asymmetric division of the zygote into a larger suspensor and smaller terminal cell may be of overriding significance.
Smith (1988b) has argued that relatively high frequencies of uniparental progenies indicate that the plastids may not be randomly mixed and may remain separated spatially in the zygote. So uniparental progeny result from exclusion of one parent's plastids from the terminal cell, while failure of exclusion leads to biparental progeny. As the paternal progeny were the more abundant, the maternal plastids were excluded more often. In a consideration of several models, TilneyBassett (1970) was not in favour of the spatial hypothesis, but a model combining the spatial disposition of plastids together with their propensity to mix appears to be worthy of further discussion in relation to the current information from pelargonium.

In regard to type I families, we can assume that the zygotes contain a sizeable population of plastids with a majority derived from the maternal parent. The actual number in the egg probably varied owing to a combination of both polygenic control and a Gaussian distribution around the means, whereas with the constant male parent variation within the male gamete is only Gaussian. As a result of these sources of variation the ratio of maternal: paternal plastids also varies. Now when the zygote divides, we asume that only a fraction of the plastids enter the terminal cell; in other words the population is sampled. Clearly, the chance of including plastids of both kinds depends on the total population, the sample size, and the relative frequencies of the two types of plastid. We therefore expect a threshold ratio of maternal: paternal plastids above which the likelihood of male plastids being included in the sample is negligible and below which there is an increasing likelihood of sampling male plastids with decreasing ratio, and this is exactly what we found. As long as the maternal frequency remains greater than the paternal plastid frequency, we expect the chance of sampling both types of plastid to be less than purely maternal and more than purely paternal and this was what we found, indeed it was characteristic for type I plants. Nevertheless, if the sample size is small enough, and fewer than the number of male plastids, it is to be expected that some samples will contain only male plastids accounting for the paternal embryos, and this too we regularly found.

An additional reason for the regular occurrence of paternal embryos would be if the plastid population was not well mixed, and with the location of its components variable. In our data, whether from type I or type II populations, families with no biparental progeny were common, and among the 
biparental progeny there was a steep decline from a high frequency of individuals with very unequal proportions of maternal and paternal plastids towards a low frequency of individuals approaching an equal plastid ratio. It was previously argued (Tilney-Bassett and Birky, 1981) that the high frequency of unequal proportions was an expected consequence of drift, but if the plastids should have little turnover this explanation would be inadequate. An alternative is that the paternal plastids remain clustered together within their original cytoplasm from where they only sometimes, and then only gradually-one at a time, migrate into the cytoplasmic arena of the maternal plastids. Yet sometimes the whole cluster of paternal plastids manages to displace the maternal plastids from the location that is most favourably placed to enter the terminal cell.

We suspect that spatial distribution and/or sample size prior to zygote division is important in Oenothera. Among our numerous type I families over 50 included one or more paternal embryos even though their maternal:paternal plastid percentage ratio was $>20: 1$; yet in Oenothera $\mathrm{G} \times \mathrm{W}$ crosses, with ratios of $<2: 1$, there were no paternal progeny. This is an extraordinary contrast. How could the Oenothera crosses fail to produce any paternal embryos when the proportion of paternal plastids was much greater than is apparently the case in Pelargonium? It seems likely that the critical difference is in the spatial distribution of plastids. Thus it is conceivable that in Oenothera the maternal plastids are localized in a very favourable position in the zygote for subsequent entry into the terminal cell, and although the paternal plastids may join them to a lesser or greater extent they never succeed in displacing them all. By contrast, it appears that in Medicago it is the paternal plastids that travel to the more favourable position. But like Pelargonium, and unlike Oenothera, the more favourably situated plastid cluster in Medicago is sometimes displaced by the plastids of the other parent, although more often, after $\mathrm{G} \times \mathrm{W}$ crosses in all these genera, a partial mixing of the plastids leads to biparental embryos.

The most striking feature of $\mathrm{W} \times \mathrm{G}$ crosses is that, although the reciprocal of $\mathrm{G} \times \mathrm{W}$ crosses, the majority of the progeny are usually green. The green plastids are generally more successful than the white irrespective of the direction of the cross. This suggests that, whatever the numerical or positional advantage pertaining to either type of plastid, there remains an opportunity for some further adjustment owing, if not to the incompatibility that is sometimes observed between plastids of different species within the same cell (Kumar and Cocking, 1987), then at least to their lack of equality. Whatever happens, the effect is to make the ratios approach 1:1 among type II families. Yet the expected increased frequency of biparental progeny was not found. This is explicable on the assumption that maternal and paternal plastids remain poorly mixed, and if only a small sample enters the terminal cell the requisite plastid number is easily supplied by either constituent. It might then be simply a matter of chance as to which plastid cluster is in the favoured position.

We still do not have the answer as to the mechanism for the control of biparental plastid inheritance. But what has emerged from this discussion is that there are several factors that are likely to be significant, and the relative importance of these probably vary from one species to another. A simple universal explanation is unlikely.

\section{REFERENCES}

ABDEL-WAHAB, O. A. L. AND TILNEY-BASSETT, R. A. E. 1981 The role of plastid competition in the control of plastid inheritance in the zonal Pelargonium. Plasmid, 6, 7-16.

BIRKY, C. W. JR. 1983. Relaxed cellular controls and organelle heredity. Science, 222, 468-475.

BIRKY, C. W. JR., VAN WINKLE-SWIFT, K. P. SEARS, B. B., BOYTON, J. E. AND GILLHAM, N. W. 1981. Frequency distribution for chloroplast genes in Chlamydomonas zygote clones: Evidence for random drift. Plasmid 6, 173-192.

BORNER, T. \& SEARS, B. B. 1986. Plastome mutants. Plant Molecular Biology Reporter 4, 69-92.

CHIU, W. L., STUBBE, W. AND SEARS, B. B. 1988. Plastid inheritance in Oenothera: organelle genome modifies the extent of biparental plastid transmission. Current Genetics, 13 , $181-189$.

CORNU, A. AND DUlieU, H. 1988. Pollen transmission of plastid-DNA under genotypic control in Petunia hybrida Hort. J. Hered., 79, 40-44.

CORRIVEAU, J. L. AND COLEMAN, A. W. 1988. Rapid screening method to detect potential biparental inheritance of plastid DNA and results for over 200 angiosperm species. Amer. J. Bot., 75, 1443-1458.

KIRK, J. T. O. \& TILNEY-BASSETT, R. A. E. 1978. The Plastids: Their Chemistry, Structure, Growth and Inheritance, 2nd edn. Elsevier/North-Holland Biomedical Press, Amsterdam.

KUMAR, A. \& COCKING, E. C. 1987. Protoplast fusion: a novel approach to organelle genetics in higher plants. Amer. J. Bot., 74, $1289-1303$.

KUMAR, A. AND COOPER-BLAND, S. 1986. Organelle genetics of somatic hybrid-cybrid progeny in higher plants. In Man tell, S. H., Chapman, G. P. and Street, P. F. S. (eds) The Chondriome-Chloroplast and Mitochondrial Genomes, Longman, London, pp. 244-271.

MEDGYESY, P., PAY, A. AND MARTON, L. 1986. Transmission of paternal chloroplasts in Nicotiana. Molec. Gen. Genet., 204, 195-198. 
MEYER, R. AND STUBBE, w. 1974 Das Zahlenverhältnis von mütterlichen und väterlichen Plastiden in den Zygoten von Oenothera erythrosepala Borbas (syn. Oe. lamarckiana). Ber. Deutsch. Bot. Ges., 87, 29-38.

RICHTER-LANDMANN, W. 1959. Der Befruchtungsvorgang bei Impatiens glandulifera Royle unter Berücksichtigung der plasmatischen Organelle von Spermzelle, Eizelle und Zygote. Planta, 53, 162-177.

RUSSELL, S. D. 1986. Dimorphic sperm cells, cytoplasmic transmission, and preferential fertilization in Plumbago zeylanica. In: Mantell, S. H., Chapman, G. P. and Street, P. F. S. (eds) The Chondriome-Chloroplast and Mitochondrial Genomes, Longman, London, pp. 69-116.

RUSSELL, S. D. 1987. Quantitative cytology of the egg and central cell of Plumbago zeylanica and its impact on cytoplasmic inheritance patterns. Theor. Appl. Genet., 74, 693699.

SCHÖTZ, F. 1954. Uber Plastidenkonkurrenz bei Oenothera. Planta, 43, 182-240.

SCHÖTZ, F. 1968. Uber Plastidenkonkurrenz bei Oenothera. II. Biol. Zbl., 87, 33-61.

SCHÖTZ, F. 1974. Untersuchungen über die Plastidenkonkurrenz bei Oenothera, IV. Biol. Zbl., 93, 41-64.

SСнӧтZ, F. 1975. Untersuchungen über die Plastidenkonkurrenz bei Oenothera, V. Biol. Z $\mathrm{bl}$., 94, 17-26.

SEARS, B. B. 1980 . Elimination of plastids during spermatogenesis and fertilization in the Plant Kingdom. Plasmid 4, 233-255.

SMITH, S. E. 1988a. Biparental inheritance of organelles and its implications in crop improvement. Plant Breed. Rev. 6, 361-393.

SMITH, S. E. $1988 \mathrm{~b}$. Infiuence of parental genotype on plastid inheritance in Medicago sativa. (Unpublished)
THRAILKILL, K. M., BIRKY, C. W. JR., LÜCKEMANN, G. AND WOLF, K. 1980. Intracellular population genetics: Evidence for random drift of mitochondrial allele frequencies in Saccharomyces cerevisiae and Schizosaccharomyces pombe. Genetics, 96, 237-262.

TILNEY-BASSETT, R. A. E. 1970. The control of plastid inheritance in Pelargonium. Genet. Res., Cambridge, 16, 49-61.

TILNEY-BASSETT, R. A. E. 1976. The control of plastid inheritance in Pelargonium IV. Heredity, 37, 95-107.

TILNEY-BASSETT, R. A. E. 1984. The genetic evidence for nuclear control of chloroplast biogenesis in higher plants. In Ellis, R. J. (ed.) Chloroplast Biogenesis, Society for Experimental Biology Seminar Series 21, Cambridge University Press, Cambridge, pp. 13-50.

TILNEY-BASSETT, R. A. E. 1986. Plant Chimeras. Edward Arnold, London.

TILNEY-BASSETT, R. A. E. 1988. Inheritance of plastids in Pelargonium. I11: Boffey, S. A. and Lloyd, D. (eds) The Division and Segregation of Organelles, Society for Experimental Biology Seminar Series 35, Cambridge University Press, pp. 115-129.

TILNEY-BASSETT, R. A. E. AND ABDEL-WAHAB, O. A. L. 1982. Irregular segregation at the $\operatorname{Pr}$ locus controlling plastid inheritance in Pelargonium: Gametophytic lethal or incompatibility system? Theor. Appl. Genet., 62, 185-191.

TILNEY-BASSETT, R. A. E. AND BIRKY, C. W. JR. 1981. The mechanism of the mixed inheritance of chloroplast genes in Pelargonium: Evidence from gene frequency distributions among the progeny of crosses. Theory. Appl. Genet., $60,43-53$. 